\title{
Differential Associations of Walking and Cycling with Body Weight, Body Fat and Fat Distribution - the ACTI-Cités Project
}

\author{
Mehdi Menai $^{a}$ Hélène Charreire ${ }^{a, b}$ Pilar Galan ${ }^{a} \quad$ Chantal Simon $^{c}$ \\ Julie-Anne Nazare ${ }^{c}$ Camille Perchoux ${ }^{c, d}$ Christiane Weber ${ }^{\mathrm{e}}$ \\ Christophe Enaux ${ }^{f}$ Serge Hercberg ${ }^{a} g$ LéopoldFezeu ${ }^{a}$ \\ Jean-Michel Oppert ${ }^{\mathrm{a}, \mathrm{h}}$ \\ a Université Paris 13, Sorbonne Paris Cité - EREN (Equipe de Recherche en Epidémiologie \\ Nutritionnelle), U1153 Inserm, Inra, Cnam, Centre de Recherche en Epidémiologie et \\ Biostatistiques; CRNH IdF, Bobigny, France; ${ }^{b}$ Université Paris Est, LabUrba, Département \\ de Géographie, UPEC, Créteil, France; ' ${ }^{C}$ Carmen, Inserm U1060/Université de Lyon 1/INRA

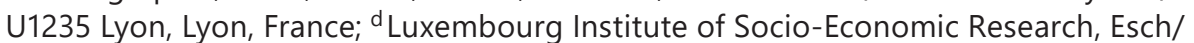

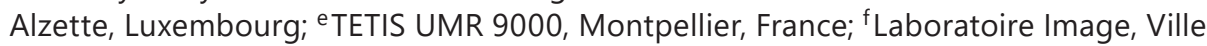 \\ et Environnement, Université de Strasbourg, Strasbourg, France; ${ }^{9}$ Department of Public \\ Health, Hôpital Avicenne (AP-HP), Bobigny, France; 'horbonne Université, Department of \\ Nutrition Pitié-Salpêtrière Hospital (AP-HP), Center for Research on Human Nutrition Ile- \\ de-France (CRNH IdF), Institute of Cardiometabolism and Nutrition (ICAN), Paris, France
}

\section{Keywords}

Obesity · Physical activity · Epidemiology

\begin{abstract}
Background: Research on the associations between walking and cycling with obesity-related phenotypes is growing but relies mostly on the use of BMI. The purpose of this study was to analyze associations of walking and cycling behaviors assessed separately with various obesity markers in French adults. Methods: In 12,776 adult participants (71.3\% women) of the ongoing NutriNet Santé web-cohort, we assessed by self-report past-month walking and cycling (for commuting, errands and leisure), and obesity measures were taken during a visit at a clinical center (weight, height, waist circumference, and percent body fat by bioimpedance). Results: In analyses not taking into account other types of physical activity (household, leisure), walking more than $2.5 \mathrm{~h} /$ week was associated in women with lower weight $(-1.8 \mathrm{~kg})$, waist circumference $(-1.7 \mathrm{~cm})$ and percent body fat $(-1.1 \%)$ (all $p<0.001)$. Cycling more than $1.5 \mathrm{~h} /$ week was associated in men and women with lower weight $(-4.3$ and $-1.4 \mathrm{~kg}$, respectively), waist circumference $(-4.4$ and $-2.1 \mathrm{~cm}$, respectively), and percent body fat $(-2.5$ and $-1.9 \%$ respectively) (all $p<0.001)$. Results were unaltered when analyses were further ad-


Menai et al.: Differential Associations of Walking and Cycling with Body Weight, Body Fat and Fat Distribution - the ACTI-Cités Project

justed on household and leisure physical activity. Conclusion: These results show important differences between walking and cycling in their association with obesity markers in men and women. These findings provide some evidence for the need to consider separately walking and cycling when designing public health measures for prevention of obesity in adults.

(C) 2018 The Author(s)

Published by S. Karger GmbH, Freiburg

\section{Introduction}

Obesity is responsible for more than 3 million death per year worldwide [1] and is the third cause of death in middle- and high-income countries [2]. Worldwide, it was recently shown that obesity prevalence increased from 1975 to 2014 by $7.6 \%$ and $8.5 \%$ in men and women, respectively [3]. In France, obesity in adults increased from $8.5 \%$ in 1997 to $15 \%$ in $2012[4,5]$. Obesity is an independent risk factor for a variety of chronic health conditions, including coronary heart disease, hypertension, diabetes, and certain cancers [6]. Importantly, health risks associated with obesity depend on body fat distribution, which cannot be assessed only with BMI $[7,8]$.

Causes of obesity are multifaceted and include biological factors, individual behaviors (primarily dietary intake and physical activity level) and obesogenic environments. One of the strategies to increase physical activity is to find specific active behaviors to be included in daily routines. In such a context, active transportation is now considered as a key element of physical activity promotion for health [9]. Walking and cycling in everyday life may help to achieve sufficient physical activity for health benefits at the population level [10] and have societal benefits such as positive impact on traffic, air pollution, and greenhouse gas emissions [11]. It has been shown in large cohort studies that walking and/or cycling were associated with lower body weight, obesity prevalence, and percent body fat [12-15]. In a recent study on data from the NutriNet-Santé Web-cohort [16], we showed that walking at least 30 min/day or practicing any amount of cycling was associated with a lower BMI among French adults [17]. As indicated by a recent meta-analysis based on 23 randomized controlled trials published up to September 2012 (for a total of 1,201 participants), results from intervention studies also showed that being in the walking group was associated with a significantly lower BMI [18]. However, beyond associations with BMI, relations of walking and cycling separately with measured body fat or with markers of body fat distribution have been little studied. A better understanding of these differential associations may help in the near future to design more specific public health recommendations.

Consequently, the objectives of the present cross-sectional study, in a large sample of French adults, were to study walking and cycling separately and in combination in relation to obesity markers (weight, BMI, waist circumference, and percent body fat).

\section{Material and Methods}

\section{Ethics Statement}

This study was approved by the 'Comité National Informatique et Liberté' (CNIL n908450, n 909216 and DR-2012-576). The NutriNet-Santé Study (see below) was approved by the Institutional Review Board of the French Institute for Health and Medical Research (IRB Inserm no 0000388FWA00005831). Written informed consent was obtained from all subjects. All procedures were approved by the 'Consultation Committee for the Protection of Participants in Biomedical Research' (C09-42 on May 5, 2010) and the CNIL (no 1460707). 
Menai et al.: Differential Associations of Walking and Cycling with Body Weight, Body Fat and Fat Distribution - the ACTI-Cités Project

\section{Study Design and Participants}

We analyzed cross-sectional data from participants in the NutriNet-SantéStudy, a web-based prospective observational cohort launched in France in 2009, focusing on the relationships between nutrition and chronic disease risk as well as on the determinants of dietary behaviors. Volunteers aged 18 years or older (age range 18-96 years) living in France (urban and rural areas) and having access to the internet fill in self-administered web-based questionnaires at baseline and then regularly during follow-up using a dedicated, secured website. A detailed description of the NutriNet-Santé study has been published previously [16].

Participants in the present study were subjects from the NutriNet-Santé cohort who completed the Sedentary, Transportation, and Activity Questionnaire (STAQ), a questionnaire on habitual physical activity, administered from February 15 to August 15, 2013 ( $\mathrm{n}=55,694 ;$ 48.5\% participation rate) in the framework of the ACTI-Cites project $[17,19]$. This questionnaire assessed physical activity and active transport in everyday life over the past 4 weeks [20]. Among the participants who filled in this questionnaire, 1,730 were excluded because of physical limitations to mobility, such as self-reported motor impairment $(n=927)$ or self-reported limitations to walking (item 'Ability to walk $100 \mathrm{~m}$ ' $\mathrm{n}=803$ ). In addition, we excluded participants who were pregnant $(n=730)$ or reported implausible physical activity values $(n=2,817)$.

All participants in the NutriNet-Santé study were invited, on a voluntary basis, for a visit in one of the local clinical centers specifically set up for biological sampling and clinical examination in each region (as of November 2012, 44 hospital-located centers were participating in the collection). Electronic and paper written informed consents were obtained from all subjects attending the visit.

From the 19,621 participants who underwent the clinical examination up to June 1, 2014, 14,426 had completed the STAQ. Finally, we excluded 1,650 participants who had missing data regarding the covariates used in multivariable analyses, reaching a final sample of 12,776 subjects whose data were analyzed in the present study.

\section{Measures}

Walking, Cycling, and Other Types of Physical Activity

The STAQ is based on the Recent Physical Activity Questionnaire (RPAQ) [21], with additional specific items on transport-related activities and sedentary behaviors by domains (commuting to work and for errands), as described in detail elsewhere [20]. Total walking and cycling during the past 4 weeks (sum of commuting, errands, and leisure in hours/week) were each divided into a three-class variable; the nonpractice, below the median excluding the null values, and above the median excluding the null values. The median values were $2.5 \mathrm{~h}$ /week for walking and $1.5 \mathrm{~h} /$ week for cycling (median values were similar for men and women). We considered it was not possible not to practice walking; consequently, the non-practice of walking was defined as between 0 and $30 \mathrm{~min} /$ week. In the present study, when analyses were performed using other thresholds for walking (the non-practice of walking being defined by $0 \mathrm{~h} /$ week or $1 \mathrm{~h} /$ week), similar results were observed (data not shown).

For household physical activity, a question was asked about the time spent per week usually doing moderate to vigorous activities such as cleaning the floor or using vacuum. Based on the median value, this variable was dichotomized as $\pm 7 \mathrm{~h}$ /week (i.e., $1 \mathrm{~h}$ /day). Leisure time physical activity was obtained by summing weekly durations of each activity reported in the leisure section of the questionnaire (except for walking for leisure and cycling for leisure that they were part of the walking and cycling variables). The resulting leisure time physical activity variable was categorized based on WHO guidelines for physical activity [22], resulting in a three-class variable $(0-0.5 \mathrm{~h} /$ week, $>0.5$ and $\leq 2.5 \mathrm{~h} /$ week, and $>2.5 \mathrm{~h} /$ week).

Anthropometry and Body Composition

Clinical examination was performed by a trained technician and included standardized measures of weight, height, waist circumference, and body fat. Height was measured with a calibrated wall-mounted stadiometer to the nearest $0.5 \mathrm{~cm}$ [23]. Waist circumference was measured using an inelastic tape as the circumference midway between the lower ribs and iliac crests on the midaxillary line. Weight (to the nearest $0.1 \mathrm{~kg}$ ) and percent body fat were measured using a bioimpedance analyzer (BC-418MA, TANITA ${ }^{\odot}$, Tokyo, Japan), with participants wearing indoor clothes, barefoot.

\section{Covariates}

Sociodemographic variables were assessed by a self-administered questionnaire completed by participants at inclusion. Data included age, gender, educational level (classified as $<2$ years of university, $\geq 2$ years of university), and home address. Weekly number of working hours was asked during the past 4 weeks, and 
Menai et al.: Differential Associations of Walking and Cycling with Body Weight, Body Fat and Fat Distribution - the ACTI-Cités Project

the weekly mean duration was computed. The type and amount of physical activity at work was assessed with a 4-category qualitative question from the STAQ (sedentary, standing, manual, or heavy manual work), and a binary variable was created (sedentary or standing work, manual or heavy manual work). A 5-class work variable was then created (do not work, have a sedentary job and work less than $35 \mathrm{~h} /$ week, have a sedentary job and work more than $35 \mathrm{~h} /$ week, have a strenuous job and work less than $35 \mathrm{~h} /$ week, have a strenuous job and work more than $35 \mathrm{~h} /$ week).

Leisure screen time activities were derived from questions asking participants to report hours/day (excluding working hours) usually spent on an average work/non-work day over the past 4 weeks watching television, DVDs or videos and using a computer, a tablet or playing screen-based video games [24]. The sum of all the mean durations per week of these activities was categorized as less than $2 \mathrm{~h} /$ day, between 2 and 4 $\mathrm{h}$ /day and more than $4 \mathrm{~h} /$ day.

Urban density (number of inhabitants/surface) of the residential neighborhood was obtained from the French Census databases (www.insee.fr) and categorized as follows: 0-300 people $/ \mathrm{km}^{2}$ (rural area), 300-2,000 people $/ \mathrm{km}^{2}$ (urban density), and more than 2,000 people $/ \mathrm{km}^{2}$ (high urban density). The perception of presence of destinations/amenities around participant residence was assessed by a separate questionnaire (administered at the same period as the STAQ) on perception of residential environment. The question included 9 amenities (grocery store, supermarket, bank, post office, school, bakery, restaurant, coffee shop, and pharmacy) and a binary variable was created ( $\leq 6$ and $>6$ unique destinations, based on the median value).

Each year, participants are asked to complete three non-consecutive self-administered web-based 24-hour dietary records, the days for which are randomly assigned during a 2-week period (2 days during the week and 1 day during the weekend). All foods and beverages consumed at breakfast, lunch, dinner, and at all other occasions are recorded. The participants are asked to estimate the portion size for each reported food and beverage item using validated photographs [25]. Daily dietary intakes of energy, lipids, and alcohol are then calculated using the NutriNet-Santé food composition table, which includes more than 2,500 different foods [26, 27]. Dietary variables used in the analyses included total energy intake (kcal/day), fat intake (\%), and alcohol consumption. The alcohol consumption variable was divided into 3 classes (none, between 0 and $16 \mathrm{~g} /$ day, more than $16 \mathrm{~g} /$ day).

\section{Statistical Analyses}

Continuous variables were summarized as means \pm standard deviations (SD), and categorical variables as percentages. Associations between practice of walking, cycling, household or leisure physical activity with body weight, BMI, waist circumference and percent body fat were assessed using two-step multivariate linear regression models. Model 1 included all covariates with one specific physical activity (walking, cycling, household or leisure). Model 2 included all covariates and all physical activity. Results were expressed as betas (standard error; SE). We initially identified potential correlates and covariables in models through bivariate analyses and existing literature. Covariates included age, educational level, smoking status, leisure time and household physical activity, leisure screen time, urban density, destinations around residential address, type of work as well as daily energy, lipid, and alcohol intake. Models were also adjusted on the time period between physical activity reporting and clinical examination. Among all studied covariates, only sex was found to be a significant interaction factor (data not tabulated). Consequently, we also performed analyses stratified on sex. For all analyses, the significance level was set at 0.05 , and all tests were two-tailed. All statistical analyses were performed using SAS software (version 9.3; SAS Institute Inc., Cary, NC, USA).

\section{Results}

\section{Characteristics of the Study Population}

Subjects were mostly middle-aged, with a majority of women, and $63.9 \%$ being highly educated. Employment was reported for $56.5 \%$ of men and $65.8 \%$ of women, which was of a sedentary type for a majority of them. Overall, walking was performed by $76.0 \%$ of participants and cycling by $19.1 \%$. For participants who reported working and walking, time spent walking for commuting to work accounted for $49.6 \%$ of the total time spent walking $(68.7 \%$ for cycling) (table 1). 
Menai et al.: Differential Associations of Walking and Cycling with Body Weight, Body Fat and Fat Distribution - the ACTI-Cités Project

Table 1. Characteristics of the study population

\begin{tabular}{|c|c|c|}
\hline & $\begin{array}{l}\text { Men }(n=3,669) \\
\% \text { or mean }(S D)\end{array}$ & $\begin{array}{l}\text { Women }(n=9,107) \\
\% \text { or mean }(S D)\end{array}$ \\
\hline Age & $58.3(12.9)$ & $52.8(13.1)$ \\
\hline Education ( $\geq 2$ years of university) & 61.0 & 65.1 \\
\hline Current smoker & 10.2 & 10.7 \\
\hline Sedentary work & 47.2 & 60.5 \\
\hline \multicolumn{3}{|l|}{ Physical activity } \\
\hline \multicolumn{3}{|l|}{ Walking } \\
\hline Less than $0.5 \mathrm{~h} /$ week & 24.8 & 23.6 \\
\hline Between 0.5 and $2.5 \mathrm{~h} /$ week & 37.7 & 38.2 \\
\hline More than $2.5 \mathrm{~h} /$ week & 37.5 & 38.2 \\
\hline \multicolumn{3}{|l|}{ Cycling } \\
\hline No & 72.6 & 84.2 \\
\hline Between 0 and $1.5 \mathrm{~h} /$ week & 13.8 & 7.9 \\
\hline More than $1.5 \mathrm{~h} /$ week & 13.7 & 7.8 \\
\hline \multicolumn{3}{|l|}{ Walking and cycling } \\
\hline Neither walking $(<0.5 \mathrm{~h} /$ week $)$ nor cycling $(0 \mathrm{~h} /$ week $)$ & 18.5 & 20.5 \\
\hline Either walking ( $\geq 0.5 \mathrm{~h} /$ week) or cycling ( $>0 \mathrm{~h} /$ week) & 60.3 & 66.9 \\
\hline Both walking ( $\geq 0.5 \mathrm{~h} /$ week) and cycling (>0 h/week) & 21.2 & 12.7 \\
\hline \multicolumn{3}{|l|}{ Leisure-time physical activity } \\
\hline $0-0.5 \mathrm{~h} /$ week & 18.9 & 26.8 \\
\hline $0.5-2.5 \mathrm{~h} /$ week & 32.2 & 38.6 \\
\hline More than $2.5 \mathrm{~h} /$ week & 48.9 & 34.6 \\
\hline Household activity ( $>7 \mathrm{~h} /$ week) & 32.9 & 48.3 \\
\hline \multicolumn{3}{|l|}{ Leisure screen time (per day) } \\
\hline $0-2 \mathrm{~h}$ & 18.7 & 26.9 \\
\hline $2-4 \mathrm{~h}$ & 39.8 & 37.8 \\
\hline More than $4 \mathrm{~h}$ & 41.5 & 35.4 \\
\hline \multicolumn{3}{|l|}{ Diet } \\
\hline Energy intake, kcal/day & 2,295 (569) & $1,804(471)$ \\
\hline Lipids, \% & $36.8(6.4)$ & $38.4(6.5)$ \\
\hline \multicolumn{3}{|l|}{ Alcohol } \\
\hline No & 21.3 & 36.8 \\
\hline Between 0 and $16 \mathrm{~g} /$ day & 39.2 & 31.6 \\
\hline More than $16 \mathrm{~g} /$ day & 39.5 & 31.6 \\
\hline \multicolumn{3}{|l|}{ Obesity markers } \\
\hline Weight, kg & $77.5(12.1)$ & $63.0(11.7)$ \\
\hline Height, cm & $174.8(6.7)$ & $162.5(6.1)$ \\
\hline BMI, $\mathrm{kg} / \mathrm{m}^{2}$ & $25.3(3.6)$ & $23.9(4.4)$ \\
\hline Waist circumference, $\mathrm{cm}$ & $90.7(10.6)$ & $79.8(11.1)$ \\
\hline Percent body fat & $20.3(6.5)$ & $29.9(7.6)$ \\
\hline Obesity (BMI $\left.\geq 30 \mathrm{~kg} / \mathrm{m}^{2}\right), \%$ & 9.1 & 8.9 \\
\hline
\end{tabular}

Association of Walking, Cycling, and Other Physical Activity with Obesity Markers

Globally, there was a linear trend towards lower adiposity markers with higher level of walking and cycling, with a sex interaction. Models fitted separately for walking, cycling, leisure or household separately (model 1 ) or with all physical activity variables in the same model (model 2) showed similar results (tables 2, 3). Compared to women who walked less 
Menai et al.: Differential Associations of Walking and Cycling with Body Weight, Body Fat and Fat Distribution - the ACTI-Cités Project

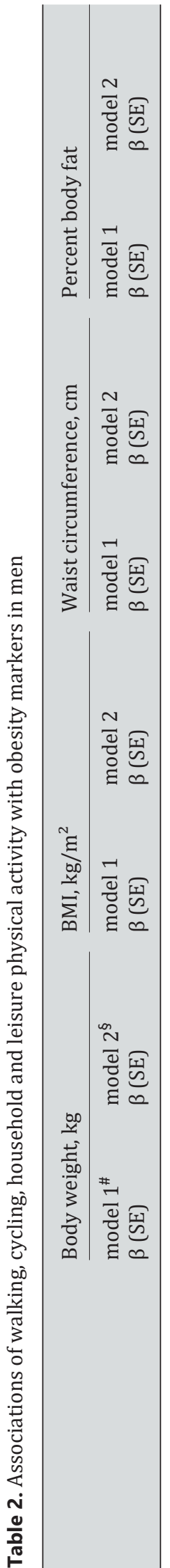

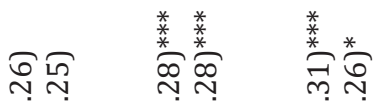

仓ं

กิণ

î

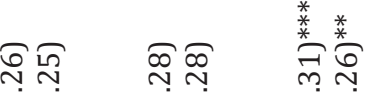

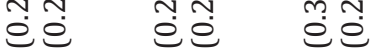

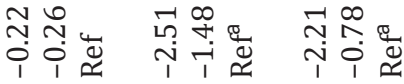

苦茲

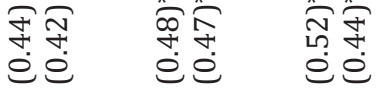

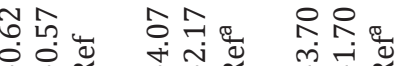

iิ氏

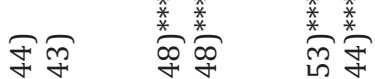

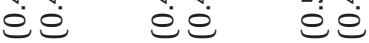

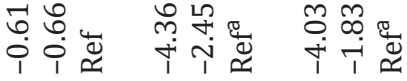

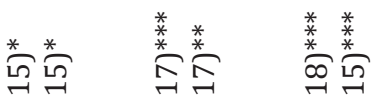

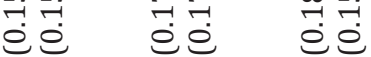

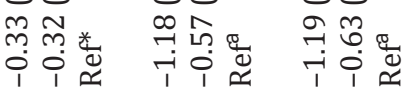

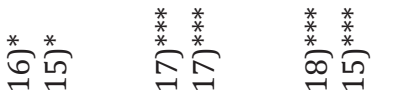

ปี

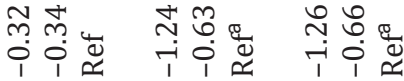

กิ

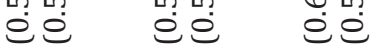

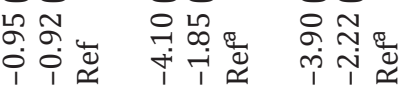

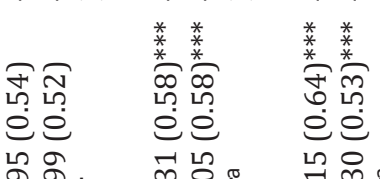

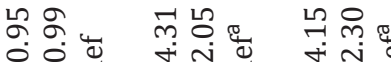

I广®

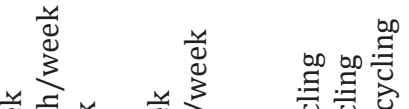

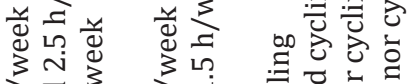

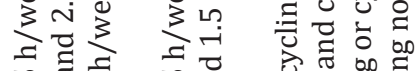

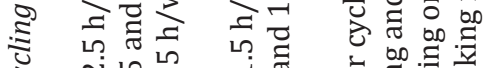

仓ั

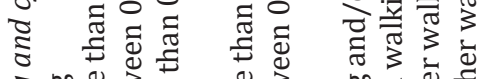

马.

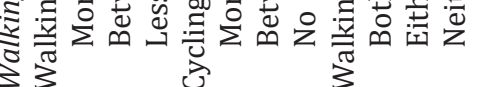

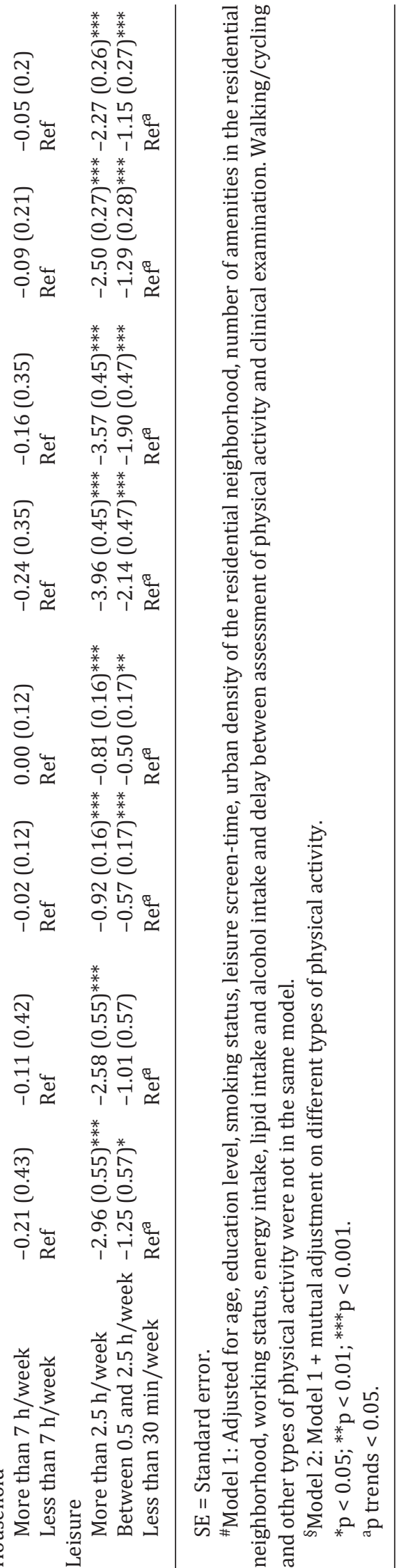


Menai et al.: Differential Associations of Walking and Cycling with Body Weight, Body Fat and Fat Distribution - the ACTI-Cités Project

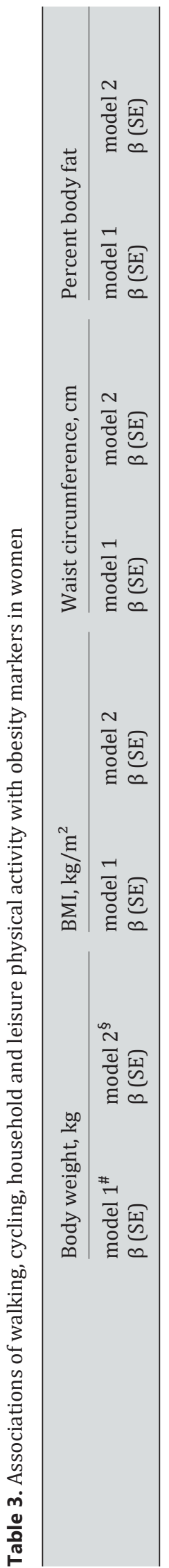

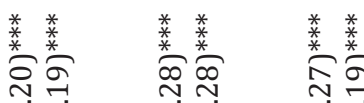

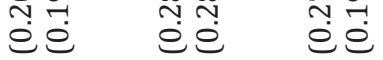

资

iิ

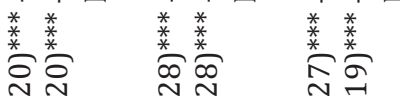

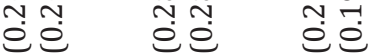

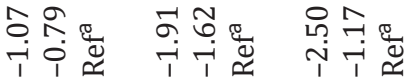

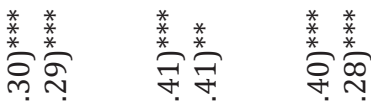

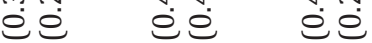

웜

†ェ

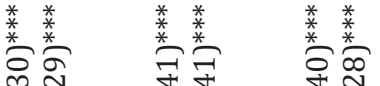

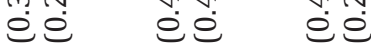

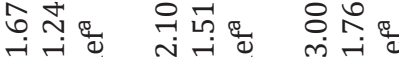

†े 궈

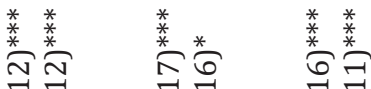

苞

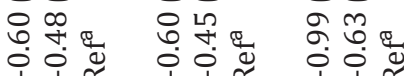

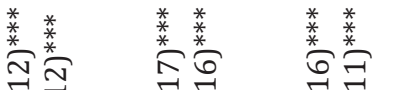

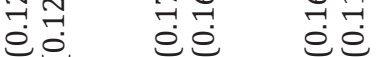

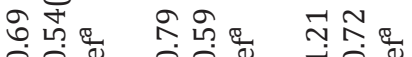

i话

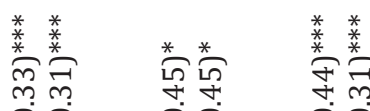

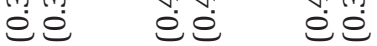

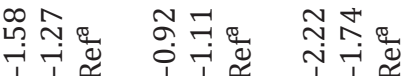

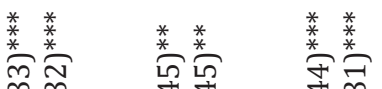

仓ं巳

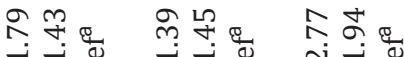

†宁宁宁宁
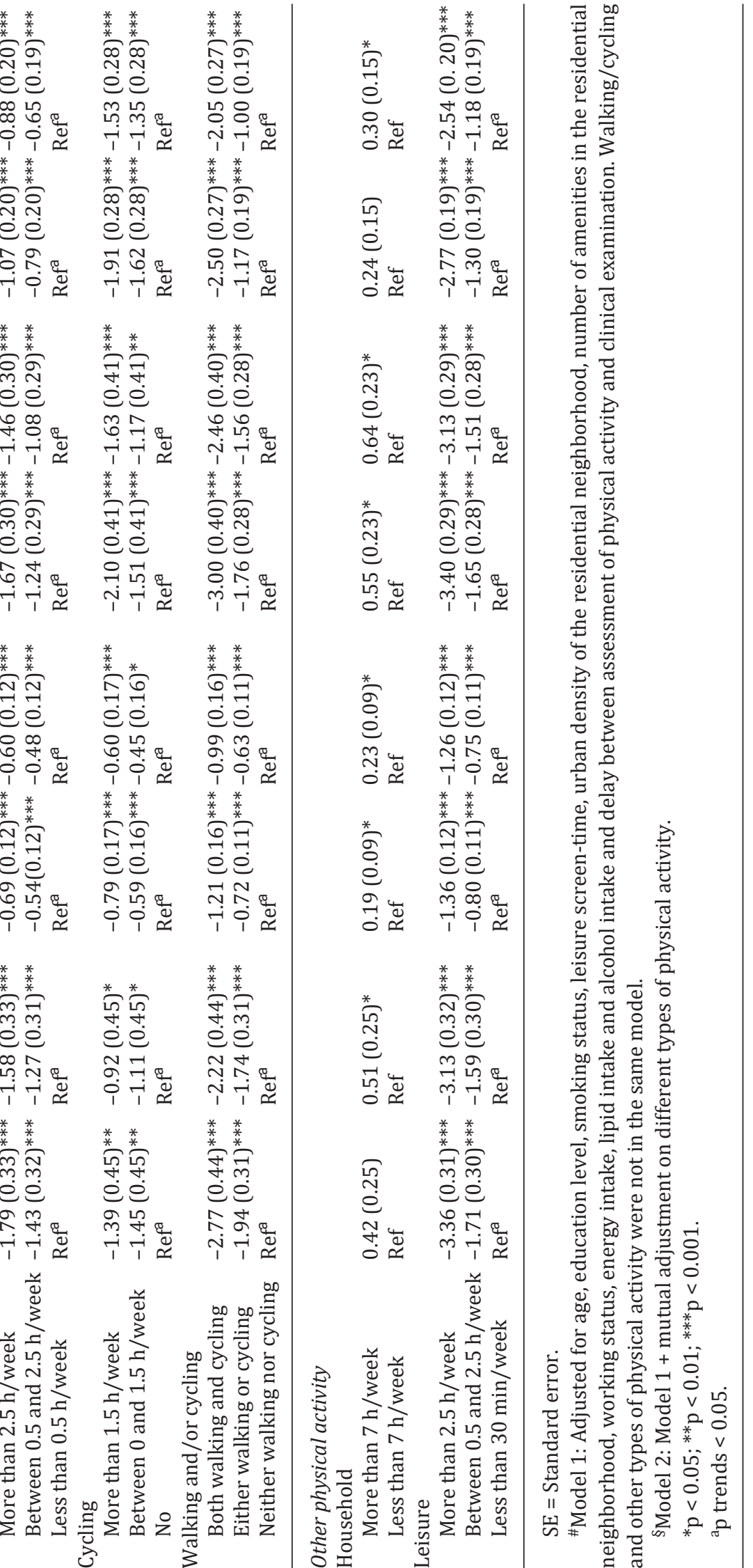
Menai et al.: Differential Associations of Walking and Cycling with Body Weight, Body Fat and Fat Distribution - the ACTI-Cités Project

than $30 \mathrm{~min} /$ week, those who walked more had significantly lower body weight, BMI, waist circumference, and percent body fat (all $\mathrm{p} \leq 0.001$ ). The same trend was seen in men but only for BMI $(\mathrm{p}<0.03)$. Moreover, women walking more than $2.5 \mathrm{~h} /$ week had lower obesity markers than those who walked between $0.5 \mathrm{~h}$ and $2.5 \mathrm{~h} /$ week. Also, men and women who reported cycling had significantly lower obesity markers compared to their counterparts who did not cycle (all $\mathrm{p} \leq 0.01$ ). On average, more than $1.5 \mathrm{~h} /$ week of cycling was associated with a lower body weight of $4.10 \mathrm{~kg}$ in men and of $0.92 \mathrm{~kg}$ in women. Also, weight, BMI, waist circumference, and percent body fat were lower when the duration of cycling was higher.

\section{Discussion}

In a sample of middle-aged French adults, we found that different obesity markers were associated with walking, and these associations were more consistent in women than in men. Obesity markers were also associated with cycling in both sexes, with greater effects seen in men (up to a factor 4). Analyses were performed according to sex, with multivariable adjustment including socioeconomic indicators, different domains of physical activity and sedentary behaviors, residential environment characteristics, and dietary intake. These results bring new evidence in favor of considering walking and cycling as distinct behaviors towards potential effects on body weight and health status.

The relations of walking and cycling with obesity markers observed in our study are consistent with a growing and recent body of evidence. Data from the Nurses' Health Study showed a 16-year association of increase in walking and cycling with lower weight gain over time in premenopausal women [28], while another recent 3-year longitudinal study did not find such association [29]. In a nationally representative survey of UK residents $(n=12,796)$, Laverty et al. [30] found negative associations for walking and cycling to work (assessed separately) with both BMI and likelihood of overweight or obesity. Similar results were found in an Indian population by Millett et al. [14] as well as recently for BMI and percent body fat in a large UK population [12]. Our findings extend these recent results by showing specific associations according to sex with waist circumference and percent body fat.

Our results highlight that time spent walking can possibly provide sex-specific benefits on obesity markers. We found associations with walking mostly in women. Limited evidence exists from large observational cohorts to compare with this finding, and previous results appear largely inconsistent. Recently, Flint et al. [12] showed in more than 72,000 men and 83,000 women from the UK Biobank that using mainly walking or cycling for commuting, compared to using the car, was associated with lower BMI and percent body fat in both sexes. Several studies focused their analyses according to sex using pooled walking and cycling variables to describe overall active transportation behavior and found a negative association with BMI, percent body fat, or waist circumference for both sexes [31-33]. Only Gordon-Larsen et al. [13] found dissimilar associations according to sex in 2,364 participants of the CARDIA study, with lower odd ratios to be obese or overweight for participants reporting active commuting only in men. The lack of a significant association between walking and obesity markers in men in our study could be due to potential specific confounding factors which were not properly measured and which would differ according to sex. Further studies would be needed to better understand these sex differences in the relation between walking and obesity markers.

We found that cycling behaviors seemed to be more strongly associated with obesity markers than walking. Few studies have investigated the differential association between different mode of transportation (including cycling) and obesity markers, probably because of the low prevalence of cycling in these studies [34]. The recent study from the UK Biobank 
found that, compared to participants who only used the car, associations with BMI and percent body fat seemed stronger for those using active transport compared to public and active transport [12]. Lusk et al. [28] showed that the longitudinal weight gain change was negatively associated with increase of cycling in premenopausal women, but not with increase of slow walking. Although the evidence is scarce and indirect, it is plausible that cycling has greater impact on obesity markers than walking for equal duration, based on higher physical activity-related energy expenditure induced by cycling compared to walking [35]. Studies are needed to compare absolute effects on obesity markers of walking and cycling separately for comparable travelled distances.

\section{Strengths and Limitations}

Strengths of this study include a large sample size allowing assessment of both walking and cycling (according to sex) in relation to anthropometric and body composition indicators. Some limitations must be noted. Measures of walking and cycling were self-reported, which might introduce misclassification bias mostly because of documented over-reporting of physical activity [36]. Estimates of self-reported physical activity duration are subject to recall errors, social desirability bias, and difficulties with correctly estimating the amount of individual walking and cycling. The relatively low prevalence of cycling in our cohort did not allow us to detail more specifically the combined effects of walking and cycling with obesity markers. Environmental variables such as weather or slope were not available at the whole country level at the time of the study. Our sample included proportionally more women and more individuals of high educational levels, as observed in general in volunteer-based studies [37]. For these reasons extrapolation of these findings must be done cautiously. Finally, the cross-sectional design of this study does not allow causal interpretations of the results.

\section{Conclusion}

In this study, we showed that active transportation associations with obesity markers may differ across walking or cycling behavior and according to sex. In women, walking was associated with lower obesity markers, and the associations of combined walking and cycling with obesity markers seem to be more pronounced compared to only cycling. In men, cycling, but not walking behaviors, was found to be associated with obesity markers. Although cause and effect relationships cannot be inferred from cross-sectional data, this study emphasizes the importance of public health measures aimed at increasing active transportation in preventive strategies to tackle obesity.

\section{Authors' Contributions}

Authors' contributions: Conceived and designed the experiments: JMO CS HC CW CE PG SH. Performed the experiments: HC JMO PG SH. Analyzed the data: MM. Wrote the paper: MM JMO LF. Involved in interpreting results and editing the manuscript: MM HC PG CS JAN CP CW CE SH JMO LF. 
Menai et al.: Differential Associations of Walking and Cycling with Body Weight, Body Fat and Fat Distribution - the ACTI-Cités Project

\section{Acknowledgements}

This work is part of the ACTI-Cités project (coordinator: JM Oppert) carried out with financial support from the French National Cancer Institute (Institut National du Cancer, INCa) through the Social sciences and humanities and public health program (2011-1-PL-SHS-10).

The NutriNet-Santé cohort study is funded by the following public institutions: Ministère de la Santé, Institut de Veille Sanitaire (InVS), Institut National de la Prévention et de l'Education pour la Santé (INPES), Fondation pour la Recherche Médicale (FRM), Institut National de la Santé et de la Recherche Médicale (INSERM), Institut National de la Recherche Agronomique (INRA), Conservatoire National des Arts et Métiers (CNAM) and Paris 13 University. Menai Mehdi was funded by a grant from Fondation Le Roch - Les Mousquetaires.

The funding sources played no role in the design and conduct of the study; the collection, management, analysis and interpretation of the data; or the preparation, review, and approval of the manuscript by coauthors.

The authors thank Younes Esseddik, Paul Flanzy, Mohand Ait Oufella, Yasmina Chelghoum, and Than Duong Van (computer scientists), Florence Charpentier (dietitian), Elise Martin (communication assistant), Nathalie Arnault, Véronique Gourlet, Fabien Szabo, Laurent Bourhis, and Stephen Besseau (statisticians), and Rachida Mehroug (logistics assistant) for their technical contribution to the NutriNet-Santé study.

Study registration: The NutriNet-santé study was registered under the EudraCT number 2013000929-31.

\section{Disclosure Statement}

The authors declare that they have no competing interests.

\section{References}

$\checkmark 1$ Must A, Spadano J, Coakley EH, Field AE, Colditz G, Dietz WH: The disease burden associated with overweight and obesity. JAMA 1999;282:1523-1529.

2 World Health Organization: Global Health Risks: Mortality and Burden of Disease Attributable to Selected Major Risks. 2009. www.who.int/healthinfo/global_burden_disease/GlobalHealthRisks_report_full. pdf?ua\&equal;1 (last accessed June 6, 2018).

-3 Di Cesare M, Bentham J, Stevens GA, Zhou B, Danaei G, Lu Y, Bixby H, Cowan MJ, Riley LM, Hajifathalian K, Fortunato L, Taddei C, Bennett JE, Ikeda N, Khang YH, Kyobutungi C, Laxmaiah A, Li Y, Lin HH, Miranda JJ, Mostafa A, Turley ML, Paciorek CJ, Gunter M, Ezzati M: Trends in adult body-mass index in 200 countries from 1975 to 2014: a pooled analysis of 1698 population-based measurement studies with 19.2 million participants. Lancet 2016;387:1377-1396.

4 Charles MA, Eschwege E, Basdevant A: Monitoring the obesity epidemic in France: the Obepi surveys 19972006. Obesity (Silver Spring) 2008;16:2182-2186.

5 Eschwege E, Charles M, Basdevant A, Moisan C, Bonnélye G, Touboul C, Goulhamousen N, Crine A: Obépi 2012 Enquête épidémiologique nationale sur le surpoids et l'obésité. Enquête Inserm/Kantar Health/Roche 2012. www.roche.fr/content/dam/roche_france/fr_FR/doc/obepi_2012.pdf (last accessed June 6, 2018).

6 World Health Organization: Preventing and Managing the Global Epidemic. Report of a World Health Organization Consultation. WHO Technical Report Series 2000;894:1-253. www.who.int/nutrition/publications/ obesity/WHO_TRS_894/en/ (last accessed June 6, 2018).

7 Despres JP, Lemieux I: Abdominal obesity and metabolic syndrome. Nature 2006;444:881-887.

8 Nazare JA, Smith J, Borel AL, Aschner P, Barter P, Van Gaal L, Tan CE, Wittchen HU, Matsuzawa Y, Kadowaki T, Ross R, Brulle-Wohlhueter C, Almeras N, Haffner SM, Balkau B, Despres JP: Usefulness of measuring both body mass index and waist circumference for the estimation of visceral adiposity and related cardiometabolic risk profile (from the INSPIRE ME IAA study). Am J Cardiol 2015;115:307-315.

9 World Health Organization: A Guide for Population-Based Approaches to Increasing Levels of Physical Activity. 2007. www.who.int/dietphysicalactivity/PA-promotionguide-2007.pdf (last accessed June 6, 2018).

10 Shephard RJ: Is active commuting the answer to population health? Sports Med (Auckland) 2008;38:751-758.

11 Commission of the European Communities: Green Paper.from the Commission to the Council, the European Parliament, the European Economic and Social Committee and the Committee of the Regions. Adapting to Climate Change in Europe - Options for EU Action. 2007. www.preventionweb.net/files/11162_LexUriServ.pdf (last accessed June 6, 2018). 
Menai et al.: Differential Associations of Walking and Cycling with Body Weight, Body Fat and Fat Distribution - the ACTI-Cités Project

12 Flint E, Cummins S: Active commuting and obesity in mid-life: cross-sectional, observational evidence from UK Biobank. Lancet Diabetes Endocrinol 2016;4:420-435.

13 Gordon-Larsen P, Boone-Heinonen J, Sidney S, Sternfeld B, Jacobs DR Jr, Lewis CE: Active commuting and cardiovascular disease risk: the CARDIA study. Arch Intern Med 2009;169:1216-1223.

14 Millett C, Agrawal S, Sullivan R, Vaz M, Kurpad A, Bharathi A, Prabhakaran D, Reddy KS, Kinra S, Smith GD: Associations between active travel to work and overweight, hypertension, and diabetes in India: a crosssectional study. PLoS Med 2013;10.

15 Physical Activity Guidelines Advisory Committee: Physical Activity Guidelines Advisory Committee Report, 2008. Washington, DC,US Department of Health and Human Services, 2008, pp A1-H14.

16 Hercberg S, Castetbon K, Czernichow S, Malon A, Mejean C, Kesse E, Touvier M, Galan P: The Nutrinet-Sante Study: a web-based prospective study on the relationship between nutrition and health and determinants of dietary patterns and nutritional status. BMC Public Health 2010;10:242.

17 Menai M, Charreire H, Feuillet T, Salze P, Weber C, Enaux C, Andreeva VA, Hercberg S, Nazare JA, Perchoux C, Simon C, Oppert JM: Walking and cycling for commuting, leisure and errands: relations with individual characteristics and leisure-time physical activity in a cross-sectional survey (the ACTI-Cites project). Int J Behav Nutr Phys Act 2015;12:150.

18 Murtagh EM, Nichols L, Mohammed MA, Holder R, Nevill AM, Murphy MH: The effect of walking on risk factors for cardiovascular disease: An updated systematic review and meta-analysis of randomised control trials. Prev Med 2015;72:34-43.

19 Feuillet T, Charreire H, Menai M, Salze P, Simon C, Dugas J, Hercberg S, Andreeva VA, Enaux C, Weber C: Spatial heterogeneity of the relationships between environmental characteristics and active commuting: towards a locally varying social ecological model. Int J Health Geogr 2015;14:12.

20 Mensah K, Maire A, Oppert JM, Dugas J, Charreire H, Weber C, Simon C, Nazare JA: Assessment of sedentary behaviors and transport-related activities by questionnaire: a validation study. BMC Public Health 2016;16: 753.

-21 Besson H, Brage S, Jakes RW, Ekelund U, Wareham NJ: Estimating physical activity energy expenditure, sedentary time, and physical activity intensity by self-report in adults. Am J Clin Nutr 2010;91:106-114.

22 World Health Organization: Global Recommendations on Physical Activity for Health. 2010. www.who.int/ dietphysicalactivity/factsheet_recommendations/ (last accessed June 6, 2018).

23 Lohman TG, Roche AF, Martorell R: Anthropometric Standardization Reference Manual. Champaign, Human Kinetics Books, 1988.

-24 Saidj M, Menai M, Charreire H, Weber C, Enaux C, Aadahl M, Kesse-Guyot E, Hercberg S, Simon C, Oppert J-M Descriptive study of sedentary behaviours in 35,444 French working adults: cross-sectional findings from the ACTI-Cités study. BMC Public Health 2015;15:379.

25 Hercberg S, Deheeger M, Preziosi P: SU-VI-MAX. Portions alimentaires Manuel photos pour l'estimation des quantités Poly Technica. Paris, Economica, 1994.

26 CNS: Table de composition des aliments - Etude NutriNet-Santé. Paris, Economica, 2013.

-27 Si Hassen W, Castetbon K, Cardon P, Enaux C, Nicolaou M, Lien N, Terragni L, Holdsworth M, Stronks K, Hercberg S, Mejean C: Socioeconomic indicators are independently associated with nutrient intake in French adults: a DEDIPAC study. Nutrients 2016;8:158.

-28 Lusk AC, Mekary RA, Feskanich D, Willett WC: Bicycle riding, walking, and weight gain in premenopausal women. Arch Intern Med 2010;170:1050-1056.

-29 Mytton OT, Panter J, Ogilvie D: Longitudinal associations of active commuting with body mass index. Prev Med 2016;90:1-7.

-30 Laverty AA, Mindell JS, Webb EA, Millett C: Active travel to work and cardiovascular risk factors in the United Kingdom. Am J Prev Med 2013;45:282-288.

-31 Barengo NC, Kastarinen M, Lakka T, Nissinen A, Tuomilehto J: Different forms of physical activity and cardiovascular risk factors among 24-64-year-old men and women in Finland.Eur J Cardiovasc Prev Rehabil 2006; 13:51-59.

-32 Flint E, Cummins S, Sacker A: Associations between active commuting, body fat, and body mass index: population based, cross sectional study in the United Kingdom. BMJ 2014;349:g4887.

-33 Kwasniewska M, Kaczmarczyk-Chalas K, Pikala M, Broda G, Kozakiewicz K, Pajak A, Tykarski A, Zdrojewski T, Drygas W: Commuting physical activity and prevalence of metabolic disorders in Poland. Prev Med 2010;51: 482-487.

34 Oja P, Titze S, Bauman A, De Geus B, Krenn P, Reger-Nash B, Kohlberger T: Health benefits of cycling: a systematic review. Scand J Med Sci Sports 2011;21:496-509.

-35 Ainsworth BE, Haskell WL, Herrmann SD, Meckes N, Bassett DR Jr, Tudor-Locke C, Greer JL, Vezina J, WhittGlover MC, Leon AS: 2011 Compendium of Physical Activities: a second update of codes and MET values. Med Sci Sports Exerc 2011;43:1575-1581.

-36 Shephard RJ: Limits to the measurement of habitual physical activity by questionnaires. Br J Sports Med 2003; 37:197-206; discussion 206.

-37 Kesse-Guyot E, Peneau S, Mejean C, Szabo de Edelenyi F, Galan P, Hercberg S, Lairon D: Profiles of organic food consumers in a large sample of French adults: results from the Nutrinet-Sante cohort study. PloS One 2013; 8:e76998. 